\title{
LA IMAGINACIÓN ENTRE CIENCIA Y LITERATURA
}

Sobre Luciana Martínez. La doble rendija. Autofiguraciones cientificas de la literatura en el Río de la Plata, Buenos Aires: Prometeo, 2019. 217 pp.

Cristian Molina

Instituto de Estudios Críticos en Humanidades Universidad Nacional de Rosario Consejo Nacional de Investigaciones Científicas y Técnicas

El 1 de diciembre de 2017 se emitió por primera vez el capítulo de la serie alemana Dark. El relato audiovisual desarrolla la historia de cuatro familias que viven en Winden, donde comienzan a suceder algunos acontecimientos extraños, habilitados por la desaparición de un niño. A medida que avanza, ese niño -al igual que muchxs personajes- comienza a vivir, multiplicándose en diferentes tiempos y planos, al punto tal de que se convierte en el viajero que lo observa en su primera incursión a unas cavernas donde las leyes del tiempo, el espacio y la relación entre energía (nuclear) y materia parecen propender a una multiplicidad que desestabiliza cualquier relato lineal de una vida. Y sin ninguna culpa por la maldad de spoilear, ese mismo niño llega, incluso, a convertirse en su propio padre. Esta sola serie basta para indicar cómo las relaciones entre ficción y ciencia, sobre todo física $y$, en particular, las complejas teorías de la cuántica, la relatividad y la teoría del caos se han convertido en un problema de la ficción 
contemporánea que satura, incluso, el proliferante mundo de las series en el presente. Basta señalar, además, cómo melodrama y saberes de la ciencia aparecen entretejiendo las complejas tramas de películas, obras teatrales e, incluso, telenovelas.

Tal es así que un estudioso de las series contemporáneas, como Jorge Carrión, propone la categoría de "ficción cuántica" para comprender no solo las problematizaciones temáticas de las series, sino su propia forma. Una que, según entiende Carrión, se entronca con las preocupaciones borgeanas por los universos paralelos, por la repetición en la que adviene una diferencia que tiende a la totalidad y que daría cuenta de la estructura serial: es decir, capítulos-entregas que difieren en su repetición pero que involucran un conjunto abierto-cerrado. No es casual, en este sentido, que sea "El jardín de los senderos que se bifurcan" el que aparezca con insistencia nombrando capítulos de series como Flash Forward (ABC 20092010), The $O A$ (Plan B enterteinment y Anonymus Content 2016-2018) o Once Upon a Time (ABC 2011-2018). En Borges, sostiene Carrión, se encuentran los comienzos de la ficción cuántica.

Y es también Borges el punto de partida que elige Luciana Martínez en La doble rendija. Autofiguraciones cientificas de la literatura en el Río de la Plata, para proponer una paradoja que se encargará de desarrollar de modo exhaustivo, inteligente y entretenido -y a contracorriente- para comprender las relaciones entre ciencia y literatura en el Río de la Plata, puntualmente, en las obras de Mario Levrero y Marcelo Cohen: 
Cuenta Rojo (un físico del Balseiro) que su motivación inicial fue indagar si acaso Borges estaba al tanto de los varios textos de la física que citaban sus relatos para ejemplificar las paradojas de los conjuntos infinitos y de la geometría fractal. Fue por eso que decidió preguntarle finalmente, ansioso, azorado, cómo había conseguido arribar hacia 1941, en "El jardín de los senderos que se bifurcan", a la misma conclusión que llegó el físico Hugh Everett recién en 1957. Ésta es: el hecho de que la materia pueda comportarse como onda y como partícula, según sea o no observada, sólo puede explicarse por la hipótesis de las realidades paralelas (p. 11).

La respuesta de Borges, señala Luciana, fue que él nada sabía de física, pero que "seguramente toda la asombrosa coincidencia se deba a la irreconocida imaginación de los físicos" (12). Es a partir de la categoría de imaginación que la lectura de Luciana se vuelve proliferantemente intensa, puesto que es en torno de ella que se permite imaginar un "estar-encomún" no solo como dispositivo político de la comunidad de los hombres que explora a partir de Levrero y Cohen, sino de diferentes saberes que parecen estar disponibles en un diálogo incesante a partir de un repertorio que los acerca y los interpela con vasos comunicantes. No es que Borges leyera física cuántica; o que la física recurriera al terreno de la ficción para avanzar en sus hipótesis, sino que en el orden de lo imaginario habría entre Borges y la física ciertas preocupaciones que estaban en común. Estar en común no es, sin embargo, ser en común, sino habilitar un con-tacto entre diferencias que genera la aparición de una comunidad donde solo pareciera haber fracturas disciplinares. Luciana asegura, así, que el surgimiento del paradigma de la cuántica habilita ciertos puntos de reunión 
con la literatura, puesto que entra en sintonía con las propias inquietudes que, desde el terreno de la ficción, venían cuestionando el concepto clásico de materia desde al menos el S XIX en el Río de La Plata. La literatura rioplatense pudo anticipar -o proponer- algunos problemas similares a los de la física, como en el caso de Borges, porque había una episteme conformada a partir de diversos saberes que intentan dar cuenta de la "inefable cosa en sî" kantiana, apelando a estados alterados de consciencia o métodos ocultistas-paranormales. De este modo, "el discurso de la literatura pelea entonces cuerpo a cuerpo, disputa a otras textualidades la fundación ontológica del universo compartido" a partir de una cosmovisión realista.

Se trata, entonces, de un estar en común entre la ciencia con la literatura, pero también con la filosofía y con saberes plebeyos y descartados de la racionalización científica, lo que habilita esos vasos comunicantes de la imaginación que afectan y contactan unos saberes con otros. En Fantasmas, Daniel Link señaló en 2009, el precario lugar que había tenido el concepto de imaginación en la crítica literaria, siendo que es el lugar privilegiado donde habitan los fantasmas, esos entes que son y no son al mismo tiempo y que son los más habilitados para pensar, en estos términos, un concepto tan complejo como el de ficción. Quizá por su raigambre medieval, asociada a la teoría del fantasma e imago, la imaginación haya tenido que esperar hasta el S XXI para retornar en diversas formulaciones que van desde "la imaginación pública" de Josefina Ludmer, hasta el concepto de imaginario de Castroriardis o, incluso, hasta la filosofía de la imaginación aristotélica de Emanuel 
Coccia. Y es justamente en un momento en que se relativiza la autonomía -como señala Luciana- o en el que se ingresa a una temporalidad posautónoma, que la imaginación se convierte en central para poder operar entre los saberes, en un estar en común habilitado por la idea de una propiedad en común de los hombres que puede permitir, en este sentido, imaginar a partir de la comunicabilidad de problemas que no son sino fantasmas que acechan bajos formas bien diversas, pero no por eso absolutamente alejadas, el presente.

Agamben, a propósito de Averroes, señala que "la imaginación recibe de este modo un rango determinante en todo sentido: en el vértice del alma individual, en el límite de lo corpóreo y lo incorpóreo, lo individual y lo común, la imaginación es la escoria extrema que la combustión de la existencia individual abandona en el umbral de lo separado y de lo eterno". Es por eso que, prosigue, el pensamiento en acto resulta del encuentro de dos elementos heterogéneos: los fantasmas individuales y la potencia única del pensamiento. La imaginación articula las potencias comunes del pensamiento único con fantasmas individuales. $Y$ esa es la tensión que estructura y atraviesa el libro de Luciana a partir de las relaciones entre ciencia y literatura.

Por un lado, están las potencias únicas del pensamiento que habilitan el estar en común sin ser en común de los saberes con los que trabaja. Para eso, deberá comprobar cómo la scientia rioplatense entrama un diálogo con tradiciones occidentales y orientales que articulan lo común. De ahí que tenga que abordar las limitaciones del concepto clásico de materia frente a uno cuántico, donde partícula y onda, materia 
y energía están relacionados y no dicotomizados, planteando la emergencia de objetos -los cuantos, las partículas subatómicasque escapan a la observación directa y que son algo del orden de lo inefable. Será esto, "lo inefable", el fantasma común que lance una cadena con los saberes de la literatura, la mística, la poesía universal progresiva romántica, el budismo y, finalmente, el lenguaje. Lo inefable: eso que escapa a comprobación o, incluso, a verbalización, sostiene Luciana, es el andamiaje común a la teoría cuántica, la mística, los saberes alternativos y la literatura. Por eso, la literatura escribe sobre problemas que la física no deja de ejemplificar con la literatura borgeana o, en el caso de Cohen y Levrero, la literatura apela a repertorios muy próximos a la física, relacionándolos con otros saberes, para producir ficción.

$\mathrm{Y}$ es en esa combinatoria de los repertorios que los escritores médiums habilitan la otra cualidad de lo imaginario: lo individual, según señalaba Agamben. Porque de lo que se trata es de la creación de realidad que siempre se ve alterada por un observador, como en el principio de incertidumbre de Heisenberg, abriendo la posibilidad de una multiplicidad de realidades paralelas a partir de la ficción. Así, Levrero, sostiene Luciana, "formula su literatura temprana en torno de la discusión acerca de los límites de la ciencia clásica", postulando una ontología del sujeto a partir de los problemas de la psicología, la parapsicología y la termodinámica. Mientras que Marcelo Cohen recurre a los elementos de la mística oriental para conjugarlos con las teorías del caos de Ilya Prigorine y los principios de la cuántica. De esta manera, emergen dos poéticas y dos modos de la ficción que, aunque parten de las 
potencias únicas del pensamiento, se singularizan en el repertorio de fantasmas que ponen en juego.

En esa tensión que habilita el estar en común de la imaginación, entiendo, Luciana también reformula algo que venimos pensando -y discutiendo- juntxs desde hace un tiempo: las relaciones problemáticas entre literaturas y culturas diferentes. Lo que permite, por un lado, el concepto de imaginación, es no centrarse prioritariamente en las tradicionales lecturas de influencias, intertextualidades, importaciones-exportaciones, o copia de modelos extranjeros, para pensar las articulaciones y desarticulaciones de repertorios de la imaginación entre literaturas que están en común. Más allá, pero no sin considerar, de los problemas de capital simbólico que las nuevas teorías comparatistas trajeron a la discusión a partir de las lecturas de Moretti y de Casanova, acá lo que se focaliza es en las combinatorias y los usos que se hacen desde la ficción de esos fantasmas disciplinares que están en común en las potencialidades epistémicas del pensamiento para hacer lo real. Así, esa otredad cultural es un modo del con-tacto, que genera un uso profanatorio de las potencias únicas del pensamiento desde el Río de La Plata. Romanticismo alemán e inglés, mística judeo cristiana, budismo y realismos europeos (por nombrar solo algunos problemas que provienen de otros repertorios culturales) dan vuelta en barco por el Delta del Plata y hacen tambalear el problema del origen y la copia para focalizar, justamente, en el devenir que construyen esos objetos, de una manera excepcional y singularísima. Sin obturar ni desconocer las relaciones con otras literaturas y culturas, ni los poderes 
simbólicos fácticos que las atraviesan, el libro propone un modo de leer que, sospecho, felizmente va más allá de la ley universal proclamada por los enfoques recientes que sostienen que la literatura mundial es "una y desigual". Lo que se propone en La doble rendija, por el contrario, es un modo de leer donde las literaturas construyen tantos mundos $-\mathrm{y}$ realidades- como sean posibles a partir de sus relaciones, que no siempre equivalen al ser en común del mundo, sino que desde la excepción y la singularidad también aspiran a proponer un estar en común con los otros, restituyendo, emancipatoriamente, una posibilidad de participar igualitariamente en la construcción de mundos, realidades y comunidad. Es casi como si ya no bastara la apuesta borgeana de proclamar la lectura de todo el mundo como tradición de nuestros destinos de sudamericanos, sino ahora también, del intento de producirlo, intervenirlo y crearlo a nuestra manera.

Termino con una anécdota. Hace menos de un año, le escribí a Luciana porque estaba trabajando sobre las energías del poema en Darío Canton, lo que me llevaba irremediablemente al terreno de la física cuántica. Esa vez charlamos mucho sobre las teorías que, incluso, en algunos artículos periodísticos, postulaban la posibilidad de comprobar la existencia del alma a partir de los quantum de energía que se liberaban al universo, que volvían a él, luego de la muerte, con información vital nuestra. Luciana me dijo algo así como "y sí, con la cuántica, puede pasar cualquier cosa". Esa convicción, entiendo, no fue peyorativa, sino que es su postulación más exacta de la realidad que construye la particular episteme de la literatura. Si este libro hubiera estado en mis manos antes de 
esa consulta, se hubieran solucionado varios problemas para la escritura de aquel artículo, porque estoy convencido de que es un aporte insoslayable, desde ahora en más, para cualquiera que, desprevenido como yo, ose tratar de dar cuenta de las relaciones entre materia y energía o entre ciencia y literatura. 